José Florencio F. Lapeña, Jr., MA, MD

Department of Otorhinolaryngology College of Medicine, University of the Philippines Manila, Philippines

Department of Otorhinolaryngology Head and Neck Surgery

East Avenue Medical Center, Diliman

Quezon City, Philippines

\section{Advancing Access to Health Information and Publication: Shifting Paradigms, Trends and Innovations}

The World Health Organization Constitution "enshrines the highest attainable standard of health as a fundamental right of every human being. The right to health includes access to timely, acceptable and affordable health care of appropriate quality... as well as the underlying determinants of health, such as ...access to health-related education and information."1 On the other hand, "social determinants of health can themselves pose barriers to education... and 'damaged brains and bodies' cannot learn optimally."2 While there are no clear-cut solutions to such multifactorial issues involving complex-systems, the sustainable developmental goals of the United Nations development agenda beyond 2015 address both health and education. ${ }^{3}$

Health research fundamentally underpins the key aspiration of the sustainable development goals to realize universal health coverage. ${ }^{3}$ It is the responsibility of researchers and publishers to make this research available and accessible to all those who need it in order to assist policymakers and practitioners to progressively realize the right to health of every global citizen. It would seem that the speed and reach of present-day information and communication technology would have facilitated the dissemination of health information. "However, despite the promises of the information revolution and some successful initiatives, there is little if any evidence that the majority of health professionals in the developing world are any better informed than they were 10 years ago." 4 This observation made over a decade ago still holds true today.

How can we advance access to health information and publication in our current "glocal" situation? How can the health information produced by research conducted by our students, residents and fellows, be shared with all those who may need and use the information? The Philipp J Otolaryngol Head Neck Surg has been actively pursuing multiple means of ensuring the availability of our research and innovation through traditional means including indexing on various Index Medici and databases. While our visibility has increased dramatically in the 10 years of our editorship, we need to explore new paradigms, trends and innovations especially with regard the social media. This includes using Facebook, Twitter, Linkedln and RSS feeds, to name a few. It also calls us to consider the transition to a full open access model and adopting Creative Commons licenses.

It is timely that the Asia Pacific Association of Medical Journal Editors (APAME) will explore this very theme of shifting paradigms, trends and innovations in advancing access to health information and publication in the forthcoming APAME2015 Annual Convention and Joint Meeting with the Western Pacific Region Index Medicus at the Sofitel Philippine Plaza and WHO
Correspondence: Prof. Dr. José Florencio F. Lapeña, Jr. Department of Otorhinolaryngology

Philippines

Phone (632) 5548467

Telefax (632) 5244455

Email lapenajf@upm.edu.ph

Reprints will not be available from the author.

The author declared that this represents original material that is not being considered for publication or has not been published or accepted for publication elsewhere, in full or in part, in print or electronic media; that the manuscript has been read and approved by the author, that the requirements for authorship have been met by the author, and that the author believes that the manuscript represents honest work. 
Western Pacific Region Office from August 24-26 (http://apame2015. healthresearch.ph) in conjunction with the Global Health Forum 2015 at the Philippine International Convention Center (http://www.forum2015. org).

Close to a thousand editors, reviewers, authors, researchers, librarians, and publishers of medical journals from Asia Pacific states, local delegates representing various institutions and organizations, including the Department of Science and Technology - Philippine Council for Health Research and Development (PCHRD), Department of Health, University of the Philippines Manila, Medical and Health Librarians Association of the Philippines (MAHLAP), the Philippine Medical Association, the Philippine Nursing Association, the Philippine Dental Association and others will exchange ideas in three days of meetings, scientific sessions and workshops. At the same time, the over 70 conjoint Forum 2015 sessions across 2 tracks covering 6 themes will provide "a platform where several other thousand key global actors in health gather to learn, debate and shape the global agenda on research and innovation for health, to arrive at new solutions that are driving health equity and socio-economic development."

Whether you are a beginning researcher or a seasoned scientist, a novice trainee or senior subspecialist, a community-based health worker or health policy-maker, there will be something for you to learn and share at these meetings that recognize "people (are) at the center of health research and innovation." Medical and health professions students, ORL-HNS residents and consultants of all training and academic institutions are particularly enjoined to participate in this rare opportunity that will benefit us as well as the people we serve.

Meet me at the Forum!

1. World Health Organization. "The right to health" Fact sheet №323 Reviewed November 2013. Cited 10 May 2015. Available at: http://www.who.int/mediacentre/factsheets/fs323/en/.

2. Lapeña JF. "From Alma Ata to Dakar: health for all, education for all" Philipp J Otolaryngol Head Neck Surg. 2012 Jan - Jun; 27(1):4-5.

3. Open Working Group of the General Assembly on Sustainable Developmental Goals. Document A/68/970, United Nations Department of Economic and Social Affairs. Cited 22 April 2015. Available at http://undocs.org/A/68/970

4. Godlee F, Pakenham-Walsh N, Ncayiyana D, Cohen B, Packer A. "Can we achieve health information for all by 2015?" Lancet 2004 Jul; 364(9430):295-300. DOl: http://dx.doi.org/10.1016/ S0140-6736(04)16681-6.
} 